\title{
Clinical and Radiological Predictability of Aditus Patency in Mucosal COM with Sclerosed Mastoid: An Analytical Study
}

\author{
${ }^{1}$ Arvind Varma, ${ }^{2}$ Tripti Maithani, ${ }^{3}$ Alok Kumar Agrahari, ${ }^{4}$ Apoorva Kumar Pandey, ${ }^{5}$ VP Singh
}

\begin{abstract}
Objectives: To evaluate the predictability of aditus patency in mucosal chronic otitis media (COM) with sclerosed mastoid using clinical and radiological tests.
\end{abstract}

Study design: Prospective study.

Materials and methods: Thirty-five cases of mucosal COM with sclerosed mastoid were taken for antrotomy with tympanoplasty. The preoperative evaluation of aditus patency was done using clinical examination, inflation deflation test for Eustachian tube function and high-resolution computed tomography (HRCT) temporal bone. The intraoperative patency was tested by water test.

Results: This study shows that there is statistically insignificant correlation between duration of discharge, tympanosclerosis and Eustachian tube function with aditus patency. There is statistically significant relationship between HRCT temporal bone and aditus patency ( $p<0.0001)$.

Conclusion: High-resolution computed tomography temporal bone is a reliable predictor for aditus patency and we recommend routine use in sclerosed mastoid before all tympanoplasties for best results.

Keywords: Aditus patency, Antrotomy, Water test.

How to cite this article: Varma A, Maithani T, Agrahari AK, Pandey AK, Singh VP. Clinical and Radiological Predictability of Aditus Patency in Mucosal COM with Sclerosed Mastoid: An Analytical Study. Int J Otorhinolaryngol Clin 2015;7(3):121-124.

Source of support: Nil

Conflict of interest: None

\section{INTRODUCTION}

Aditus ad antrum plays an important role in ventilation of mastoid air cell system. Although middle ear aeration is related to Eustachian tube function; aditus also plays a vital role. Aeration of mastoid is an important factor in outcome of tympanoplasty. The lack of an aerated mastoid at the time of tympanoplasty may be a significant source of failure in mucosal chronic otitis media (COM) with

\footnotetext{
${ }^{1}$ Assistant Professor, ${ }^{2}$ Professor, ${ }^{3}$ Senior Resident

${ }^{4}$ Associate Professor, ${ }^{5}$ Professor and Head

1-5Department of ENT, Shri Guru Ram Rai Institute of Medical and Health Sciences, Dehradun, Uttarakhand, India
}

Corresponding Author: Arvind Varma, Assistant Professor Department of ENT, Shri Guru Ram Rai Institute of Medical and Health Sciences, Dehradun, Uttarakhand, India, Phone: 9627786755 e-mail: drvarmaarvind@gmail.com sclerosed mastoid. Aereation of middle ear results through two pathways: via the Eustachian tube anteriorly and via the tympanic isthmus. Epitympanic compartments receive their aereation via the large tympanic isthmus between the medial part of the posterior incudal ligament and the tensor tendon. The aeration pathway from the Eustachian tube directly leads to the mesotympanic and hypotympanic spaces, whereas the epitympanum is away from direct air stream and is only aereated through the tympanic isthmus. ${ }^{1-3}$ Therefore, it appears that the obstruction of the aditus ad antrum would contribute the pathogenesis and accentuate pathological condition in mucosal COM. Moreover, it interferes with the aereation of the epitympanum and contribute to failure following tympanoplasty. ${ }^{3-5}$

To see the patency of aditus ad antrum intraoperatively antrotomy is performed. Antrotomy is not necessary for successful repair of central perforation. However, adding an antrotomy to tympanoplasty improves clinical results. This is because patients who have an aerated mastoid have improved results from tympanoplasty, in part because of increased volume and pressure buffer created by open mastoid cavity. The primary argument in favor of antrotomy has been improvement in middle ear aereation through clearance of diseased mucosa and tympanosclerotic patches, thereby contributing to success of tympanoplasty results. Those who oppose antrotomy argue that it is not just unnecessary for treating mucosal $\mathrm{COM}$ with sclerosed mastoid but also increases patients risk to injury of vital structures with little or no extra advantage in results. Till date, there are no strict guidelines when to perform antrotomy in dry perforation in inactive mucosal COM with sclerosed mastoid. Moreover, if antrotomy adds more benefits should it be performed in all mucosal COM with sclerosed mastoid or only with those with some signs or criteria?

Ruhl and Pensak ${ }^{6}$ concluded that antrotomy should only be considered in failed cases of tympanoplasty and in radiologically sclerosed mastoid or with evidence of soft tissue in mastoid, aditus or epitympanum. But, it is difficult to identify a blocked aditus preoperatively.

Keeping this in mind, this study was performed to evaluate the factors which might give a direct or indirect evidence of aditus patency and, thereby avoiding antrotomy in cases of patent aditus. 


\section{MATERIALS AND METHODS}

This prospective clinical study was performed in department of ENT in a tertiary care center and teaching hospital between December 2012 and June 2015. After obtaining legal consent for study, 35 patients who were diagnosed as mucosal COM with sclerosed mastoid on radiograph were taken into the study group. All patients underwent detailed clinical examination, pure tone audiometery, inflation deflation test for Eustachian tube function and high-resolution computed tomography (HRCT) temporal bone.

\section{Preoperative Assessment of Aditus Patency}

In history, the duration of discharge was categorized into two groups: one less than 3 years and another greater than 3 years. By otoendoscopy (Fig. 1), assessment was made for presence or absence of tympanosclerosis and edematous or congested middle ear mucosa.

Inflation deflation test for Eustachian tube function in perforated tympanic membrane was performed by impedance audiometer (MAICO MI34). The impedance audiometer is programmed to increase or decrease the middle ear pressure. The patient is asked to swallow repeatedly and the middle ear pressure is recorded graphically. Changes in middle ear pressure is recorded as step ladder graph and this is considered as normal. If some residual pressure persists even after five swallows the tubal function is considered to be partially impaired. If positive or negative middle ear pressure cannot be neutralized at all by repeated swallowing then the Eustachian tube function is considered to be grossly impaired.

High-resolution computed tomography temporal bone was performed by taking both axial and coronal cuts for detailed anatomical evaluation including aditus patency (Figs 2 and 3).

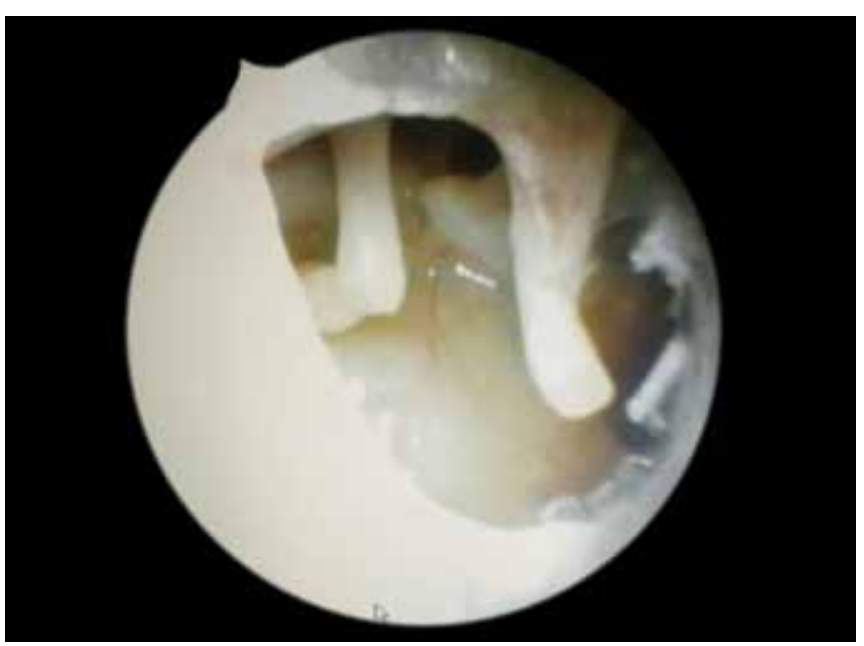

Fig. 1: Otoendoscopy showing mucosal type of chronic otitis media

\section{Intraoperative Assessment of Aditus Patency using Water Test}

After antrotomy, normal saline solution is instilled into the antrum with $10 \mathrm{ml}$ syringe to test whether there is free communication between the antrum and middle ear via aditus ad antrum. If there was free flow; test result was considered positive and there was no need for further exposure of the epitympanum. If the water test result was negative, an atticotomy was performed. Re-establishment of the patency of attic may require removal of pathological mucosa surrounding the ossicles (epitympenectomy) and sometimes even removal of incus. At time of surgery assessment was made of tympanosclerosis, granulations and diseased mucosa in mastoid air cell system.

Statistical analysis was done using Fisher's exact test.

\section{RESULTS}

In this study, the age group of patients was 15 to 45 years with mean age of 28.74 years and SD of 6.83 . There were 21 females and 14 males in this study.

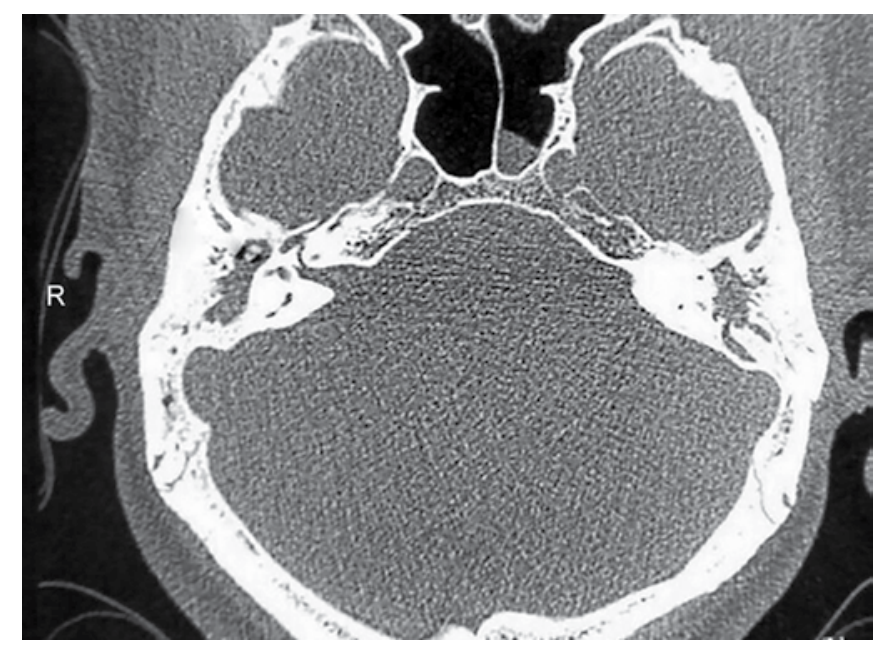

Fig. 2: High-resolution computed tomography temporal bone axial cut showing bilateral blocked aditus

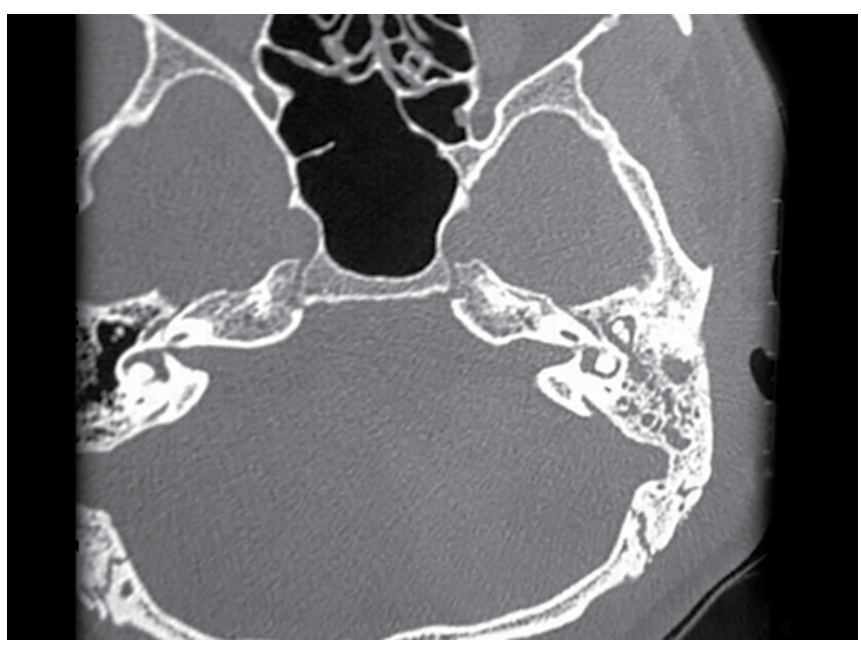

Fig. 3: High-resolution computed tomography temporal bone axial cut showing right blocked aditus 
The results obtained in our study is mentioned as follows:

\section{Duration of Discharge and Aditus Patency}

Out of 16 patients with duration of discharge $<3$ years, 11 had patent aditus and five had blocked aditus intraoperatively, whereas out of 19 patients with duration of discharge $>3$ years, 12 had patent aditus and seven had blocked aditus intraoperatively. The $\mathrm{p}$-value was 1 , which was statistically insignificant (Table 1).

\section{Tympanosclerosis and Aditus Patency}

Out of 12 patients with tympanosclerosis, five had patent aditus and seven had blocked aditus intraoperatively, whereas out of 23 patients without any tympanosclerosis, 18 had patent aditus and five had blocked aditus intraoperatively. The p-value was 0.0587 , which was statistically insignificant (Table 2).

\section{Eustachian Tube Function and Aditus Patency}

Out of 28 patients with patent Eustachian tube, 20 had patent aditus and eight had blocked aditus intraoperatively, whereas out of seven patients with blocked Eustachian tube, three had patent aditus and four had blocked aditus intraoperatively. The p-value was 0.1999, which was statistically insignificant (Table 3).

Table 1: Relationship between duration of discharge and aditus patency

\begin{tabular}{llll}
\hline $\begin{array}{l}\text { Duration of } \\
\text { discharge in } \\
\text { years }\end{array}$ & $\begin{array}{l}\text { No. of } \\
\text { cases }\end{array}$ & $\begin{array}{l}\text { Intraoperative } \\
\text { patent }\end{array}$ & $\begin{array}{l}\text { Intraoperative } \\
\text { blocked }\end{array}$ \\
\hline <3 years & 16 & 11 & 5 \\
$>3$ years & 19 & 12 & 7 \\
\hline
\end{tabular}

$p=1$ which is statistically insignificant

Table 2: Relationship between tympanosclerosis and aditus patency

\begin{tabular}{llll}
\hline $\begin{array}{l}\text { Tympano- } \\
\text { sclerosis }\end{array}$ & $\begin{array}{l}\text { No. of } \\
\text { cases }\end{array}$ & $\begin{array}{l}\text { Intraoperative } \\
\text { patents }\end{array}$ & $\begin{array}{l}\text { Intraoperative } \\
\text { blocked }\end{array}$ \\
\hline Present & 12 & 5 & 7 \\
Absent & 23 & 18 & 5 \\
\hline
\end{tabular}

$p=0.0587$ which is statistically insignificant

Table 3: Relationship between Eustachian tube function and aditus patency

\begin{tabular}{llll}
\hline ETF & Preoperative & $\begin{array}{l}\text { Intraoperative } \\
\text { patent }\end{array}$ & $\begin{array}{l}\text { Intraoperative } \\
\text { blocked }\end{array}$ \\
\hline Patent & 28 & 20 & 8 \\
Blocked & 7 & 3 & 4 \\
\hline
\end{tabular}

$p=0.1999$ which is statistically insignificant

\section{High-resolution Computed Tomography Temporal Bone and Aditus Patency}

Out of 23 patients with patent aditus on HRCT temporal bone, all 23 were found to be patent intraoperatively, whereas out of 12 patients with blocked aditus on HRCT temporal bone, all were found to be blocked intraoperatively. The $\mathrm{p}$-value was $<0.0001$, which was statistically significant (Table 4).

\section{DISCUSSION}

It is controversial that adding antrotomy to tympanoplasty improves the result of tympanoplasty in COM. Holmquist and Bergstrom ${ }^{4}$ first suggested that antrotomy improves results of tympanoplasty. Since then many studies have either supported or refuted the role of antrotomy.

Baylan et $\mathrm{al}^{7}$ suggested that antrotomy is usually not necessary for treatment of mucosal COM. They recommended antrotomy in those mucosal COM with edematous mucosa, failed cases of tympanoplasty and preoperative imaging showing sclerosed mastoid.

The lack of standard criteria for antrotomy in mucosal COM often makes judgement difficult. Many a times this leads to unnecessary antrotomy in patent aditus which not only prolongs duration of surgery, cost of the procedure and increase hospital stay but also causes inadvertent injury to vital structures.

Bahgat $^{8}$ in his study concluded that incidence of obstructed aditus was increased significantly in patients with a long duration $(>1$ year) of discharge.

In our study, we found that there is no statistically significant relationship between duration of discharge and patency of aditus $(\mathrm{p}=1)$.

Manjunath et $\mathrm{al}^{9}$ and Migrov and Volkov ${ }^{10}$ in their study confirmed that tympanosclerosis increases probability of blocked aditus.

Our study shows that there is no significant correlation between tympanosclerosis and aditus patency $(\mathrm{p}=0.0587)$.

Kurian et $\mathrm{al}^{11}$ in his study suggested that Eustachian tube inflation-deflation test is a sensitive test for predicting aditus patency in patients with dry ears but less so in patients with discharging ears.

In our study, we found no statistically significant association between ETF and patency of aditus ( $p=0.1999)$.

Table 4: Relationship between HRCT temporal bone and aditus patency

\begin{tabular}{llll}
\hline $\begin{array}{l}\text { HRCT } \\
\text { temporal }\end{array}$ & No. of & Intraoperative & $\begin{array}{l}\text { Intraoperative } \\
\text { blocked }\end{array}$ \\
bone & cases & patent & 0 \\
\hline Patent & 23 & 23 & 12 \\
Blocked & 12 & 0 & \\
\hline $\mathrm{p}<0.0001$ & which is statistically significant
\end{tabular}


Our study shows that HRCT temporal bone is a reliable predictor of preoperative aditus patency $(\mathrm{p}<0.0001)$. This finding is similar to study conducted by Ahmad et $\mathrm{al}^{12}$ for revision tympanoplasty.

Our view is that a HRCT temporal bone can be an important roadmap for tympanoplasty with sclerosed mastoid. It will provide information which can guide the hand of the most experienced surgeon on to most secure and safe path. The complexity of the ear and temporal bone justify use of HRCT temporal bone for understanding anatomy of middle ear cleft in sclerosed mastoid. A well-planned surgery carried out on the basis of imaging, which gives us the most precise knowledge of deepest structure of temporal bone can reduce the number of revision surgery. This will not only reduce the cost of surgery but also mental trauma a patient undergoes after failed surgery. In addition to patency of aditus, one can see the extent of an ossicular defect, chronic osteitis involving posterolateral bony wall of sinus tympani which can be drilled with dimond burr during surgery to eliminate chronic source of the infection.

Surprisingly, many otologists today are still proud to state that they do not need preoperative CT scan unless patient needs revision tympanoplasty. This attitude is a dangerous overestimation of one's own surgical skills because the key to safe surgery is the anticipation of possible intraoperative difficulties. ${ }^{13}$ Otologists must learn from rhinologists who routinely uses preoperative CT PNS for functional endoscopic sinus surgery.

\section{CONCLUSION}

Future of otology demands understanding of temporal bone anatomy and its pathology for best surgical results. High-resolution computed tomography of temporal bone is a reliable test for preoperative evaluation of aditus patency. It will reduce cost, duration, hospital stay and inadvertent risk of injuries by avoiding antrotomy in all cases of sclerosed mastoid for tympanoplasty. We recommend routine use of HRCT temporal bone before tympanoplasty in sclerosed mastoid for preoperative evaluation of aditus patency and also intricate anatomy of middle ear cleft for best surgical results.

\section{REFERENCES}

1. Palva T, Ramsay H. Incudal folds and epitympanic aeration. Am J Otol 1996 Sep;17(5):700-708.

2. Marchioni D, Molteni G, Presutti L. Endoscopic anatomy of the middle ear. Ind J Otolaryngol Head Neck Surg 2011 Apr;63(2):101-113.

3. Marchioni D, Alicandri-Ciufelli M, Molteni G, Artioli FL, Genovese E, Presutti L. Selective epitympanic dysventilation syndrome. Laryngoscope 2010 May;120(5):1028-1033.

4. Holmquist J, Bergstrom B. The mastoid air cell system in ear surgery. Arch Otolaryngol 1978 Mar;104(3):127-129.

5. Sade J. The correlation of middle ear aeration with mastoid pneumatization: the mastoid as a pressure buffer. Eur Arch Otorhinolaryngol 1992;249(6):301-304.

6. Ruhl CM, Pensak ML. Role of aerating mastoidectomy in noncholesteatomatous chronic otitis media. Laryngoscope 1999 Dec;109(12):1924-1927.

7. Baylan FR, Celikkanat S, Aslan A, Taibah A, Russo A, Sanna M. Mastoidectomy in non cholesteatomatous chronic suppurative otitis media: is it necessary? Otolaryngol Head Neck Surg 1997 Dec;117(6):592-595.

8. Bahgat M. Patency of the aditus ad antrum in tubotympanic chronic suppurative otitis media. Otolaryngol Head Neck Surg 2015 Feb;152(2):331-335.

9. Manjunath MK, Swarup RJ, Chary G, Shadab MD. Myringosclerosis: an indication of a blocked aditus. Ind J Otolaryngol Head Neck Surg 2012 Sep;64(3):230-232.

10. Migrov L, Volkov A. Influence of coexisting myringosclerosis on myringoplasty outcomes in children. J Laryngol Otol 2009 Sep;123(9):969-972.

11. Kurian R, Chrisolyte S, Rupa V. Inflation-deflation test as a predictor of aditus patency in patients with chronic suppurative otitis media. Ind J Otolaryngol Head Neck Surg 2009 Sep;61(3):169-172.

12. Ahmad S, El-Kady, Haroun Y, Kassem KM, Galal O. The value of computed tomography scanning in assessment of aditus ad antrum patency and choice of treatment line in revision myringoplasty. Med J Cairo Univ 2009 Sep;77(2):53-57.

13. Fish U, May JS, Linder T. Textbook of tympanoplasty, mastoidectomy and stapes surgery. 2nd ed. New York: Thieme Publication p. 38 and 298. 